\title{
MORPHOLOGICAL STUDY OF CAROTICO-CLINOID FORAMEN
}

\author{
Sandeep Mohite1, Raghunath S. More², Hemalata Mohite ${ }^{3}$ \\ ${ }^{1}$ Associate Professor, Department of Anatomy, Krishna Institute of Medical Sciences, Deemed University, Karad. \\ ${ }^{2}$ Assistant Professor, Department of Anatomy, Institute of Medical Sciences, Banaras Hindu University, Varanasi. \\ 3Tutor, Department of Anatomy, Krishna Institute of Medical Sciences, Deemed University, Karad.
}

\begin{abstract}
The anterior and middle clinoid processes of sphenoid bone are connected by a ligament called carotico-clinoid ligament, which maybe ossified forming the carotico-clinoid foramen. Ossification of some normally occurring ligaments of the human skull produces the bony bridges that connect to the clinoid processes with other surrounding structures. The ligaments are related to many anatomical structures and when ossified may cause compression of these structures.
\end{abstract}

\section{MATERIALS AND METHODS}

Total 82 adult human dried crania were studied. To select the crania, integrity of the clinoid processes was evaluated and damaged clinoid processes were excluded. The crania with unilateral or bilateral complete CCF were considered. The morphometry was performed by using vernier caliper. Anteroposterior (AP) and transverse diameters were measured. Statistical analysis was done.

\section{RESULTS}

The incidence of the presence of CCF (Carotico-clinoid foramen) was 28\%. CCF was more on right (21) than the left side (19). The AP length of the CCF on right was $0.77 \mathrm{~cm}$ while of left side it was $0.60 \mathrm{~cm}$, which was statistically significant. But, breadth on right side, it was $0.56 \mathrm{~cm}$ and on it $0.55 \mathrm{~cm}$, which was almost equal on both sides.

\section{CONCLUSION}

The presence of ossified interclinoid ligament makes the removal of the anterior clinoid process more difficult. Knowledge ab out the ossification of carotico-clinoid ligament (CCL) is important in neurosurgical operations because the presence of an ossified CCL may form a potential site for compression of internal carotid artery.

\section{KEYWORDS}

Carotico-Clinoid Ligament, Clinoid Processes, Carotico-Clinoid Foramen.

HOW TO CITE THIS ARTICLE: Mohite S, More RS, Mohite H. Morphological study of carotico-clinoid foramen. J. Evolution Med. Dent. Sci. 2016;5(61):4309-4311, DOI: 10.14260/jemds/2016/983

\section{INTRODUCTION}

The carotico-clinoid foramen is an inconstant structure, which is located in the anterior cranial fossa composed by the ossification of a fibrous ligament ${ }^{1}$ that begins on the anterior clinoid process and binds to the middle clinoid process. ${ }^{2}$ Carotico-clinoid foramen allows the passage of one of six segments of the internal carotid artery, the clinoidal segment. ${ }^{3}$ The fibrous ossification of ligaments is considered a normal physiological process that occurs with ageing; however, this process is an exception when one considers the formation of the carotico-clinoid foramen. ${ }^{4}$ Study by Hochstetter revealed the presence of this foramen in foetuses and children skulls. ${ }^{5}$ The ligaments are related to many anatomical structures and when ossified may cause compression of these structures. The carotico-clinoid and interclinoid ligaments are related to the internal carotid artery and oculomotor nerve. 6 In presence of carotico-clinoid foramen, it is impossible to retract or mobilise

Financial or Other, Competing Interest: None.

Submission 23-06-2016, Peer Review 16-07-2016,

Acceptance 23-07-2016, Published 01-08-2016.

Corresponding Author:

Dr. Raghunath Shahaji More,

Assistant Professor,

Department of Anatomy,

Institute of Medical Sciences,

Banaras Hindu University,

Varanasi-221005.

E-mail: psychiatry.more@gmail.com

DOI: $10.14260 /$ jemds $/ 2016 / 983$ the cavernous segment of carotid artery even after releasing the proximal and distal carotid rings. Preoperative recognition of carotico-clinoid foramen is important because undue retraction of cavernous segment of internal carotid artery may tear or rupture it and cause fatal cerebral infarction. ${ }^{7}$ The carotico-clinoid bridge could cause pressure on the internal carotid artery that lies in the cavernous sinus changing the morphology in the terminal end of the groove of internal carotid artery. ${ }^{8}$ Due to greater calibre of internal carotid artery in this region compared to the diameter of carotico-clinoid foramen, the possibility of headache due to compression by the foramen is high. Carotico-clinoid foramen is an important structure due to its relations with cavernous sinus and its contents, sphenoid sinus, and pituitary gland. ${ }^{4}$ Several authors studied the anatomical characteristics of Carotico-Clinoid Foramen (CCF) in different population. The Anterior Clinoid Process (ACP) is usually accessed to gain entry into the clinoid space. The ligamentous or the bony form of interclinoid ligament is important in the aneurysms surgery of the intracavernous portion of the internal carotid artery and surgery for tuberculum sellae meningiomas. ${ }^{9}$

The presence of ossified interclinoid ligament makes the removal of the anterior clinoid process more difficult and increases the risks especially in the presence of an aneurysm. Therefore, to obtain a satisfactory result from these surgeries, detailed anatomical and morphometric knowledge of the region is necessary. 


\section{MATERIALS AND METHODS}

82 adult human dried crania were studied in the Department of Anatomy, Krishna Institute of Medical Sciences Deemed University, Karad, Maharashtra. The sexing of the skulls was difficult as the skulls were from the archives of the Department of Anatomy. The occurrence of partially or completely ossified ligamentous connection between the anterior and middle clinoid processes forming the carotico-clinoid foramen was observed and noted. To select the crania, integrity of the clinoid processes was evaluated and damaged clinoid processes were excluded. The crania with unilateral or bilateral complete CCF were considered. The morphometry of each foramen was performed using a manual vernier caliper of $15 \mathrm{~cm}$ length with $0.01 \mathrm{~mm}$ accuracy. The Anteroposterior (AP) and transverse diameter were measured as shown in Fig.1. Transverse diameter was measured from the edge formed by the ossified ligament until the edge formed by the anterior clinoid process. To avoid errors in measurement, it was performed three times by the same examiner. Collected data tubulised and statistical calculations were done.

\section{RESULTS AND DISCUSSION}

The word 'clinoid' is derived from Greek word 'cline' means a bed and 'oid', which means 'similarity to'. It also derived from Greek word 'klinein' or the Latin word 'clinare' both of which mean sloped or inclined. Thus, the anterior and posterior clinoid processes surround the sella turcica like four corners of a four poster bed. ${ }^{10}$ Presence of carotico-clinoid foramen is rare and there is dearth of literature in textbooks of anatomy. The incidence of incomplete unilateral foramina varies from 8$35 \%$ while a bilateral and complete foramina are very rare found in $0.2-4 \%$ of population. ${ }^{11} \mathrm{~A}$ racial variation has also been reported in this foramen. A high incidence has been noted in Turkish (35.67\%) and Caucasian Americans (34.84\%) while a low incidence was found in Koreans (15.7\%) and Japanese (9.9\%). ${ }^{11}$ High incidence (15-38\%) of this foramina has been associated with the idiots, criminals, epileptics, and those with hormone disturbances. ${ }^{12}$ Incidence of carotico-clinoid foramen in present study was $28 \%$. It is $35.67 \%$ in the study of Erturk et al ${ }^{13}$ while very low i.e. $8.5 \%$ in the study of Freire et al. ${ }^{14}$ The incidence of CCF was more on right (21) than the left side (19). Freire et al observed 7 CCF on right side and 2 CCF on left side. ${ }^{14}$ The AP length of the CCF on right was $0.77 \mathrm{~cm}$ while of left side it was $0.60 \mathrm{~cm}$, which was statistically significant. But, breadth on right side was $0.56 \mathrm{~cm}$ and on left side was $0.55 \mathrm{~cm}$, which was almost equal on both sides. According to Freire, it was $0.55 \mathrm{~cm}$ on right and $0.54 \mathrm{~cm}$ on left side. ${ }^{14}$ Erturk et al breadth on right side was $0.52 \mathrm{~cm}$ and 0.52 $\mathrm{cm}$ on left side.13 Ozdogmus et al were performed measurements of the carotico-clinoid foramen in 50 human autopsies average of $5.14 \mathrm{~mm}$ on the right side and $5.25 \mathrm{~mm}$ on the left. There was no statistically significant difference. 4

In clinical practice, when a paraclinoid aneurysm occurs, the anterior clinoid process is removed as a treatment for this disease. This treatment is more difficult when the caroticoclinoid foramen is present causing higher possibility of serious bleeding in this region. ${ }^{15}$ After removal of the anterior clinoid process, a space is observed, the clinoid space, which has triangular form and small size. ${ }^{16}$ This space varies according to dimension of the anterior clinoid process and the internal carotid artery. ${ }^{17}$ Removal of the anterior clinoid process is one of the most critical procedures to the successful and safe management of ophthalmic segment aneurysms and tumours located in the paraclinoid region and cavernous sinus. Besides that, pneumatisation of the anterior clinoid process should be evaluated preoperatively with computed tomography to avoid complications such as rhinorrhoea and pneumocephalous. ${ }^{15}$ If the caliber of ICA is more than the diameter of CCF, there is high possibility to induce headache caused by compression of ICA in the presence of CCF. In surgery involving exposure of the clinoid segment of ICA, excision of ACP is mandatory. At that time, the presence of CCF may change the dimensions of this area. ${ }^{14}$ Oculomotor nerve may also be damaged during the removal of anterior clinoid process. ${ }^{18}$ So, serious weighing of risks and benefits of operative approaches must be done before the operation because of the magnitude of operating procedure and risks of neural and vascular injury.

\begin{tabular}{|c|c|c|c|c|}
\hline \multirow{2}{*}{} & \multicolumn{2}{|c|}{$\begin{array}{c}\text { Anteroposterior (AP) } \\
\text { length (cm) }\end{array}$} & \multicolumn{2}{c|}{$\begin{array}{c}\text { Breadth } \\
\text { (cm) }\end{array}$} \\
\cline { 2 - 5 } & Right & Left & Right & Left \\
\hline Number & 23 & 21 & 23 & 21 \\
\hline Mean & 0.77 & 0.61 & 0.56 & 0.55 \\
\hline SD & 0.26 & 0.20 & 0.093 & 0.143 \\
\hline 't' value & \multicolumn{2}{|c|}{2.32} & 0.276 \\
\hline P value & 0.024 & 0.78 \\
\hline Table 1: Showing The Anteroposterior (AP) Length, \\
Breadth of the Carotico-Clinoid Foramen(CCF) \\
\hline
\end{tabular}

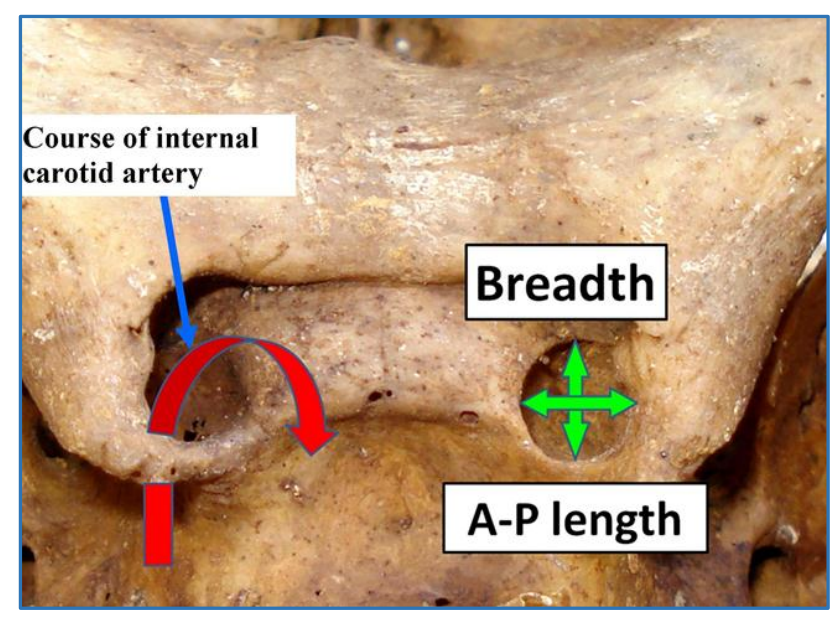

Fig. 1. Showing Bilateral Carotico-Clinoid Foramen and Method of Measurements of Anteroposterior Length and Breadth of CCF

\section{CONCLUSION}

Knowledge about the ossification of Carotico-Clinoid Ligament (CCL) is important in neurosurgical operations because the presence of an ossified CCL may form a potential site for compression of internal carotid artery leading to various neurovascular complaints. Anatomical knowledge about dimensions of CCF may be useful in cases of surgery involving removal of ACP. Prevalence and morphometric study of carotico-clinoid foramen helps the neurosurgeons for preoperative scanning and precautions can be taken to prevent fatal complications during surgery. Considering the fact that the anatomy textbooks do not provide a detailed description of the carotico-clinoid ligament or foramen, the present study proves especially relevant to neurosurgeons in day to day clinical practice. 


\section{REFERENCES}

1. Standring S. Overview of the development of the head and neck. Skull and Mandible. In: Standring S. ed. Gray's Anatomy: the anatomical basis of clinical practice. 39th edn. New York, Churchill Livingstone: Elsevier 2005:46267.

2. Sicher H, DuBrul EL. Oral Anatomy. 6th edn. Saint Louis: The C.V. Mosby Company 1975:344-78.

3. Gray H. Gray's anatomy. Williams PL. ed. 37th edn. Edinburg: Churchill Livingstone 1989:373-7.

4. Ozdogmus O, Saka E, Tulay C, et al. The anatomy of the carotico-clinoid foramen and its relation with the internal carotid artery. Surg Radiol Anat 2003;25(3-4):241-6.

5. Hochstetter F. Uber die taenia interclinoidea, die commissura ali cochlearis und die cartilago supracochlearis des menschlichen primordial craniums. Gegenbaurs Morph Jahrb 1940;84:220-43.

6. Inoue $\mathrm{T}$, Rhoton $\mathrm{AL}$, Theele $\mathrm{D}$, et al. Surgical approaches to the cavernous sinus: a microsurgical study. Neurosurgery 1990;26(6):903-32.

7. Lee HY, Chung IH, Choi BY, et al. Anterior clinoid process and optic strut in Koreans. Yonsei Medical Journal 1997;38(3):151-4.

8. Peker T, Anil A, Gulekon N, et al. The incidence and types of sella and sphenopetrous bridges. Neurosurg Rev 2006;29:219-23.

9. Linskey ME, Sekhar LN, Hirsch WL, et al. Aneurysms of the intracavernous carotid artery: natural history and indications for treatment. Neurosurgery 1990;26(6): 933-7.

10. Williams PL, Bannister LH, Berry MM, et al. Gray's anatomy in skull. 38 th edn. New York: Churchill Livingstone 2000:597-605.
11. Hasan T. Bilateral carotico-clinoid and absent mental foramen: rare variations of cranial base and lower jaw. Italian Journal Anatomy and Embryology 2013;118(3):288-97.

12. Lang J. Structure and postnatal organisation of here to fore uninvestigated and infrequent ossifications of sella turcica region. Acta Anat (Basel) 1977;99(2):121-39.

13. Erturk M, Kayalioglu G, Govsa F. Anatomy of the clinoidal region with special emphasis on the carotico-clinoid foramen and interclinoid osseous bridge in a recent Turkish population. Neurosurgery Rev 2004;27(1):22-6.

14. Freire AR, Rossi AC, Prado FB, et al. Carotico-clinoid foramen in human skulls: incidence, morphometry, and its clinical implications. Int J Morphol 2011;29(2):427-31.

15. Dolene VV. A combined epi and subdural direct approach to carotid-ophthalmic artery aneurysms. J Neurosurg 1985;62(5):667-72.

16. Gupta N, Ray B, Ghosh S. A study on anterior clinoid process and optic strut with emphasis on variations of carotico-clinoid foramen. Nepal Med Coll J 2005;7(2):141-4.

17. Sekhar LN, Burgess J, Akin O. Anatomical study of the cavernous sinus emphasising operative approaches and related vascular and neural reconstruction. Neurosurg 1987;21(6):806-16.

18. Kier EL. Embryology of the normal optic canal and its anomalies. An anatomic and roentgenographic study. Invest Radiol 1966;1(5):346-62. 